\title{
Optimal Law Enforcement under Asymmetric Information
}

\author{
Mohamed JELLAL * \\ CES Université de Rabat \\ Nuno GAROUPA ${ }^{\dagger}$ \\ Universitat Pompeu Fabra, Barcelona
}

June 1999

${ }^{*}$ CES, Department of Economics, University of Mohammed V, Rabat, Morocco. Email: Jellal@compuserve.com

†Department d'Economia i Empresa, Universitat Pompeu Fabra, Ramon Trias Fargas 25-27, 08005 Barcelona, Spain. Phone: 34-93-542 2639. Fax: 34-93-542 1746. Email: nuno.garoupa@econ.upf.es 


\begin{abstract}
In this paper, we focus on the problem created by asymmetric information about the enforcer's (agent's) costs associated to enforcement expenditure. This adverse selection problem affects optimal law enforcement because a low cost enforcer may conceal its information by imitating a high cost enforcer, and must then be given a compensation to be induced to reveal its true costs. The government faces a tradeoff between minimizing the enforcer's compensation and maximizing the net surplus of harmful acts. As a consequence, the probability of apprehension and punishment is usually reduced leading to more offenses being committed.

We show that asymmetry of information does not affect law enforcement as long as raising public funds is costless. The consideration of costly raising of public funds permits to establish the positive correlation between asymmetry of information between government and enforcers and the crime rate.
\end{abstract}

JEL: K4.

Keywords: fine, probability of detection, asymmetry of information. 


\section{Introduction}

Most models of law enforcement, since Becker (1968), assume symmetric information between government and enforcers. That corresponds to an ideal public law enforcement context as described by Landes and Posner (1975). Becker and Stigler (1974) have argued that private enforcement might be advantageous because public enforcement creates incentives to bribery which undermine deterrence. Landes and Posner (1975) have proposed that public enforcement may be superior to private enforcement in many contexts, be-

cause precisely public enforcers can more easily enforce the combination of high fines and low probabilities of detection which Becker (1968) showed to be optimal. The discussion between private and public enforcement has been followed up by Friedman (1984), Shavell (1993) and Garoupa and Klerman (1999).

Asymmetry of information between the government and a public enforcer and its impact of the cost structure of enforcement has not been discussed in the literature. Polinsky (1980) first attended at the cost structure of enforcement. He has shown that a problem with private agents is that by increasing the likelihood of punishment, the pool of offenders is reduced making the enforcement less profitable. Consequently, private enforcers have an incentive to manipulate apprehension and detection so that there is a sufficiently profitable pool of offenders. Garoupa (1997b) made additional improvement by considering the possibility of type I error (that is, convicting the innocent), and showing that private agencies have also a clear incentive to commit type I errors to boost revenues undermining criminal deterrence. Such remarks make public enforcement more attractive.

Realistically, public enforcement is not decided by a single actor, but by different agents, in particular, public enforcers and a government. An enforcement agency is more likely to have a comparative advantage in enforcement (detection and investigation) than the government. Through its operating activities, the agency obtains private information; information that is not available to the government (the principal). This information symmetry poses a serious problem of implementing an optimal enforcement policy (within the public enforcement model). In this paper, we focus on the problem created by asymmetric information about the enforcer's (agent's) costs 
associated to enforcement expenditure. Hence this is an adverse selection problem (in the jargon of incentive theory). The enforcement cost depend on several factors related to the nature of the crime and known to the enforcer (the agent) but only imperfectly observed by the principal (assumed to be a benevolent government). Therefore, a low cost enforcer may conceal its information by imitating a high cost enforcer, and must then be given an economic compensation -information rent- to be induced to reveal its true costs. The problem to be analyzed is the design of optimal incentives to offer to the enforcer (agency of enforcement) in order to secure participation with adequate compensation.

This approach is more directly related to the public sector literature that as often characterize the public sector as inefficient due to the objectives pursued by decision makers within different branches of government. Niskanen (1994) has developed a model of public sector that assumed budget maximizing bureaus, information asymmetry between bureau and the funding source, and the granting of monopoly power to the bureaus by the funding authority. Under these conditions, it can be shown that the public sector produces at a level where the social marginal cost exceeds the marginal benefit.

Our first contribution to the theory of optimal law enforcement is the consideration of an opportunity cost in using public funds to enforce the law. The optimal sanction is different from the usual solution, that is, the harm caused by the offense inflated by the probability of apprehension and punishment (the so-called multiplier principle). Furthermore, the difference between the optimal sanction and the multiplier principle increases with the opportunity cost of raising public funds.

Under asymmetric information, an information rent must be borne by the government and paid to the enforcer. The government faces a tradeoff between minimizing the enforcer's rent and maximizing the net surplus of harmful acts. As a consequence, the probability of apprehension and punishment is usually reduced leading to more offenses being committed.

The information rent is essentially a transfer from the government to the public enforcer. In the usual utilitarian context, the optimal policy is neutral to such redistribution. Asymmetry of information does not affect law enforcement as long as raising public funds is costless. The consideration 
of costly raising of public funds permits to establish the positive correlation between asymmetry of information between government and enforcers and the crime rate.

\section{Law Enforcement}

We introduce a general function for global costs, $C(x, p)$, where $x$ is an intrinsic cost parameter, and $p$ is the probability of detection and conviction. The cost parameter is determined by the agency's technology and its private knowledge. The support $x \in[\underline{x}, \bar{x}]$ and the distribution $G(x)$ are common knowledge. We make the following assumptions:

\section{A. 1 (Monotonicity) $\partial C(x, p) / \partial x>0$}

The condition of monotonicity reduces the set of participation constraints to a single constraint, hence meaning that $\underline{x}$ is the most and $\bar{x}$ is the least cost effective.

\section{A. 2 (Single Crossing Property) $\partial^{2} C(x, p) / \partial x \partial p>0$}

The single crossing property is a sufficient condition for the local and global conditions for incentive compatibility.

\section{A. 3 (Convexity) $\partial^{2} C(x, p) / \partial p^{2}>0$}

A. $4 \partial^{3} C(x, p) / \partial x \partial p^{2} \geq 0$

A. $5 \partial^{3} C(x, p) / \partial x^{2} \partial p \geq 0$

The last two assumptions are sufficient conditions for the principal's optimization problem. 


\section{A. 6 (Monotone Hazard Rate) $d[G(x) / g(x)] / d x \geq 0$}

The monotone hazard rate (where $g($.$) is the density) is satisfied by most$ standard distributions. ${ }^{1}$ This property characterizes $G($.$) as log concave and$ can be interpreted as a decreasing returns assumption. ${ }^{2}$

\subsection{Enforcement under Symmetric Information}

In the case of symmetric information, the government (the principal) knows the cost parameter, and maximizes social welfare given by the following sum of utility of offenders and non-offenders plus the agency's utility. In the optimal law enforcement literature, social welfare generally equals the sum of individuals' expected utilities minus the harm caused by offenses minus expenditure on law enforcement ${ }^{3}$ :

$$
W=\int_{p(x) s}^{B}(b-h) d F(b)-C(x, p(x))-\lambda t
$$

where $s$ is sanction, $b$ is benefit from committing an offense distributed across the population according to $F(b)$ for $b \in[0, B], h$ is the magnitude of the harm caused by the each offense, $\lambda$ is the opportunity cost of public funds, and $t$ is (budget) transfer from citizens to the government. The monetary sanction is assumed to be costless to impose as conventional in the law enforcement literature.

\footnotetext{
${ }^{1}$ See Laffont and Tirole (1993), section 1.4. This condition is satisfied by uniform, normal, logistic, chi-squared, exponential or Laplace distributions.

${ }^{2}$ Following Laffont and Tirole (1993), a possible interpretation is that the basic technology, known to everyone, is characterized by $\bar{x}$. There can be improvements on this technology. The expression $\bar{x}-x$ is a measure of the number of such improvements. $G(x)$ is the probability that there are at least $\bar{x}-x$ improvements. The probability that there are more than $\bar{x}-x$ improvements and less than $\bar{x}-x+d x$ improvements is $g(x) d x$. Thus when decreasing to $x$ from $\bar{x}, g(x) / G(x)$ is the conditional probability that there are no more improvements given that there have been already $\bar{x}-x$ improvements. The monotone hazard rate states that this conditional probability increases as the firm becomes more efficient.

${ }^{3}$ See Garoupa (1997a) and Polinsky and Shavell (1999). It is conventional in this literature to include all gains in social welfare. Some argue that the offender's gains should be excluded for moral reasons.
} 
The principal maximizes $W(p, s)$ in the probability $p$ and severity $s$ subject to the individual rationality constraint (agency's participation constraint) where we normalize the opportunity level of utility to zero: $t(x)-$ $C(x, p) \geq 0$. Since transfers are costly $(\lambda>0)$, under symmetric information $t(x)$ will be set such that the participation constraint will be binding for all types at the optimum. As a consequence, we can write $t(x)=C(x, p(x))$ for all $x \in \Omega=[\underline{x}, \bar{x}]{ }^{4}$

The principal's problem is to maximize in $p$ and $s$ :

$$
W=\int_{p s}^{B}(b-h) d F(b)-(1+\lambda) C(x, p)
$$

subject to the constraint that the sanction $s$ is upper bounded by the offender's total wealth $S$ : $0 \leq s \leq S$.

Proposition 1 Under symmetric information, the optimal enforcement policy is given by $s^{*}=S$ and

$$
p^{*}(x) S=h-\left[(1+\lambda) \partial C\left(x, p^{*}\right) / \partial p\right] /\left[S f\left(p^{*} S\right)\right]
$$

\section{Proof}

Standard. See Garoupa (1997a). $\square$.

Note that for $\lambda>0$ there is a new term given by $\lambda[\partial C(x, p) / \partial p] /\left[S f\left(p^{*} S\right)\right]$ which represents social cost since transfers are costly because they induce distortions elsewhere (in terms of taxation, administrative costs) in other productive sectors.

The interpretation of the optimal policy is standard: the marginal benefit from deterrence (in terms of avoided harm) equals the social marginal cost adjusted to deterring crime (adjusted because deflated by $S f($.$) ) plus$ the expected sanction. As a consequence $p^{*}(x) S<h$, that is, at the optimum

\footnotetext{
${ }^{4}$ We have assumed that the revenues from punishing individuals given by $\int_{p(x) s}^{\infty} p(x) s d F(b)$ are distributed lump-sum. The results we present here are robust to a different specification that includes explicitly the revenues from punishing offenders.
} 
there is underdeterrence in the sense that the expected punishment borne by the offender is less than the harm borne by the victim.

\subsection{Enforcement under Asymmetric Information}

Now, the enforcer (agent) is assumed to know her/his own type $x$. The government is unable to observe the type, but knows the range $x \in \Omega=$ $[\underline{x}, \bar{x}]$ and the distribution of types, given by the probability density function $g(x)$. Therefore, in this case, the government will recognize that if it tried to implement the first-best solution, the enforcer would have incentives to overstate her/his costs to obtain a rent. Hence, in designing an optimal law enforcement policy, the government is restricted to make contracts (menu) contingent on variables that are verifiable and observable to both parties, say the probability of enforcement.

The revelation principal states that the government can restrict its attention to the class of mechanisms in response to which the enforcement agency reports his/her type truthfully. The government offers the self-selection mechanism, a menu of type-revealing contract in $p(x)$ and $t(x)$ that the enforcer can choose among:

$$
M=\langle x \in \Omega, p(x), t(x)\rangle
$$

Define:

$$
\begin{array}{cc}
U(x)=t(x)-C(x, p(x)) & \forall x \in \Omega \\
U(\hat{x}, x)=t(\hat{x})-C(x, p(\hat{x})) & \forall \hat{x} \in \Omega
\end{array}
$$

where $U(\hat{x}, x)$ is the rent of type $x$ when $\hat{x}$ is reported, and $U(x)=U(x, x)$ when she/he reports truthfully. Recalling that social welfare is:

$$
W=\int_{p(x) s}^{B}(b-h) d F(b)-C(x, p(x))-\lambda t(x)
$$

but since $t(x)=C(x, p(x))+U(x)$ :

$$
W=\int_{p(x) s}^{B}(b-h) d F(b)-(1+\lambda) C(x, p(x))-\lambda U(x)
$$


where the first term refers to surplus of offenses, the second term to social cost of enforcement, and the third term to the cost of rent left to the agency. Under symmetric information, the enforcer does not obtain a rent since $U(x)=0$; there is no social cost of information rent. However, under asymmetric information, we will see that we must allow a positive rent to the agent in order to obtain a truthfully cost report.

The government problem is now to maximize in $p, t$ and $s$ :

$$
W=\int_{\underline{x}}^{\bar{x}}\left\{\int_{p(x) s}^{B}(b-h) d F(b)-(1+\lambda) C(x, p(x))-\lambda U(x)\right\} d G(x)
$$

subject to:

$$
\begin{gathered}
U(x) \geq U(\hat{x}, x) \quad \forall x, \hat{x} \in \Omega \quad(I C) \\
U(x) \geq 0 \quad \forall x \in \Omega \quad(I R)
\end{gathered}
$$

and the maximal sanction constraint $0 \leq s \leq S$. We see that asymmetric information generates an additional constraint - an incentive constraint (IC).

We begin by characterizing the class of mechanisms that satisfy the incentive constraints in order to implement the allocation $\langle p(x), t(x)\rangle$ in a dominant strategy:

Proposition 2 The contract $\langle p(x), t(x)\rangle_{\Omega}$ satisfies the incentive constraints if and only if:

$$
\text { (i) } U(x)=\int_{x}^{\bar{x}} \frac{\partial C}{\partial \epsilon}(\epsilon, p(\epsilon)) d \epsilon
$$

(ii) $p^{\prime}(x) \leq 0, \forall x \in \Omega$

\section{Proof}

We could follow the approach of Laffont and Tirole (1993) but the proof is now standard; hence we give a direct (and shorter) one. Let:

$$
U(x)=\sup _{\tilde{x} \in \Omega}\{t(\tilde{x})-C(x, p(\tilde{x}))\}
$$


Therefore $U(x)$ is an upper-envelope of a linear function in $x$, then it is convex and almost everywhere, by the envelope theorem, we have:

$$
\begin{gathered}
U^{\prime}(x)=-\frac{\partial C}{\partial x}(x, p(x)) \\
U^{\prime \prime}(x)=-\frac{\partial^{2} C}{\partial x \partial p}(x, p(x)) p^{\prime}(x)
\end{gathered}
$$

Expression (2) is positive if and only if $p^{\prime}(x) \leq 0, \forall x \in \Omega$. By integration of (1) such that $U(\bar{x})=0$ (that is, the least cost effective agency obtains no rent), we get:

$$
U(x)=\int_{x}^{\bar{x}} \frac{\partial C}{\partial \epsilon}(\epsilon, p(\epsilon)) d \epsilon
$$

which is the rent left to type $x \in \Omega$.

The information rent given by (i) is decreasing in $x$, i.e. to be willing to reveal their true type, more cost effective enforcers must be rewarded with a higher rent than less cost effective enforcers. Moreover, from the monotonicity condition (ii) we can say that less cost effective enforcers provide a lower level of enforcement in order to extract a rent since:

$$
\frac{\partial U(x)}{\partial p(x)}=\int_{x}^{\bar{x}} \frac{\partial^{2} C}{\partial \epsilon \partial p(\epsilon)}(\epsilon, p(\epsilon)) d \epsilon>0
$$

by the single crossing property $A$.2. Finally, since $U(x)=t(x)-C(x, p(x))$, the transfer is:

$$
t(x)=C(x, p(x))+\int_{x}^{\bar{x}} \frac{\partial C}{\partial \epsilon}(\epsilon, p(\epsilon)) d \epsilon
$$

where the first term is the covered cost and the second term is the information rent. We can insert the rent expression in the objective function of government, and obtain the following expected social welfare:

$E W=\int_{\underline{x}}^{\bar{x}}\left\{\int_{p(x) s}^{B}(b-h) d F(b)-(1+\lambda) C(x, p(x))-\lambda \int_{x}^{\bar{x}} \frac{\partial C}{\partial \epsilon}(\epsilon, p(\epsilon)) d \epsilon\right\} d G(x)$

Integrating by parts the last term, the expected social welfare can be rewritten as:

$$
E W=\int_{\underline{x}}^{\bar{x}}\left\{\int_{p(x) s}^{B}(b-h) d F(b)-(1+\lambda) C(x, p(x))-\lambda \frac{G(x)}{g(x)} \frac{\partial C}{\partial x}(x, p(x))\right\} d G(x)
$$


The enforcement problem is now reduced to maximizing expected social welfare subject to the monotonicity constraint $p^{\prime}(x) \leq 0$ and the maximal fine constraint. We will ignore the monotonicity constraint at first, and show that the solution to the less constrained problem satisfies it:

Proposition 3 Under asymmetric information, the optimal enforcement policy is given by

$$
\tilde{p}(x) S=h-[(1+\lambda) \partial C(x, \tilde{p}) / \partial p+\Delta] /[S f(\tilde{p} S)]
$$

where

$$
\Delta=\lambda \frac{G(x)}{g(x)} \frac{\partial^{2} C}{\partial x \partial p(x)}(x, \tilde{p}(x))
$$

\section{Proof}

The optimal probability $\tilde{p}(x)$ is found by pointwise differentiation of the expected social welfare with respect to $p(x)$ and $s$ such that $0 \leq s \leq S$.

It remains to show that the solution satisfies the monotonicity condition $p^{\prime}(x) \leq 0, \forall x \in \Omega$. Define:

$$
,=h-[(1+\lambda) \partial C(x, \tilde{p}) / \partial p+\Delta] /[S f(\tilde{p} S)]-\tilde{p}(x) S
$$

Hence $\tilde{p}^{\prime}(x)=-,{ }_{x} /,{ }_{p}$ where ${ }_{p}$ is negative from the second-order condition. The sign of $\tilde{p}^{\prime}(x)$ is the sign of ${ }_{x}$ which is negative due to assumptions A.2, A.4, and A.5:

$$
,_{x}=-\left[(1+\lambda) \frac{\partial^{2} C}{\partial p \partial x}-\lambda \frac{d}{d x}\left(\frac{G(x)}{g(x)}\right) \frac{\partial^{2} C}{\partial x \partial p}-\lambda \frac{G(x)}{g(x)} \frac{\partial^{3} C}{\partial p \partial^{2} x}\right] /[S f(\tilde{p} S)] \square
$$

By comparing with the solution to the symmetric information, we see that asymmetry of information generates a new term $\Delta$-the marginal information cost for all types $x \geq \underline{x}$ - giving lower enforcement for all types. The interpretation of the optimal policy is: the marginal benefit from deterrence 
(in terms of avoided harm) equals the social marginal cost adjusted to deterring crime plus the marginal cost of rent-seeking adjusted to deterring crime plus the expected sanction.

The explanation for this distortion in $p(x)$ is that it makes less favorable for more cost effective enforcers to mimic less cost effective enforcers. Indeed, when the government reduces the intensity of enforcement, an enforcer of type $x$ finds it less favorable to mimic enforcer $\tilde{x}>x$. Choosing $\tilde{p}($.$) lower than the$ first-best level $p^{*}($.$) however implies a sub-optimal enforcement level. The$ government faces a trade-off between minimizing the enforcer's information rent $U(x)$ and maximizing the net surplus of harmful acts.

\subsection{Example}

In order to compare with the usual models of the theory of optimal law enforcement, consider $F(b)$ uniform on $b \in[0,1]$, with $h<1$ and $f()=$.1 , and consider $C(x, p)=x p$ with $x \in \Omega$. Therefore, we re-write:

$$
\tilde{p}(x) S=h-[(1+\lambda) x+\lambda G(x) / g(x)] / S
$$

For $\lambda=0$ (raising public funds is costless), we have the classical firstbest solution that the expected sanction equals $h-x / S, \forall x \in \Omega$. For $\lambda>0$, the first-best is only obtained for the most cost effective enforcer $x=\underline{x}$ since $G(\underline{x})=0$.

Corollary 1 For $\lambda>0$, there is more underdeterrence with asymmetry of information.

\section{Proof}

The degree of underdeterrence is given by $h-p(x) f$. We can derive that:

$$
\left(p^{*}-\tilde{p}\right) S=\lambda[G(x) / g(x)] / S
$$


For $\lambda>0$, it is clear that the degree of underdeterrence is higher when there is asymmetry of information because of the information rent.

We have already shown that because enforcement is costly, at the optimum, there is underdeterrence, that is, the expected sanction is less than the harm borne by victims. The degree of underdeterrence augments with asymmetry of information because enforcement is more costly in such context (given that an information rent must be paid).

Consequently, under asymmetry of information, the Becker result is reinforced. As the sanction increases, the degree of underdeterrence becomes less important. In the limit case, when the severity of punishment approaches infinite and the probability of punishment approaches zero, the fact that there is asymmetry of information is not very meaningful.

Corollary 2 For $\lambda=0$, asymmetry of information does not affect the optimal policy and does not diminish deterrence.

\section{Proof}

For $\lambda=0$ we know that:

$$
\left(p^{*}-\tilde{p}\right) S=\lambda[G(x) / g(x)] / S=0
$$

Therefore, $p^{*}=\tilde{p}$.

In the usual Polinsky and Shavell (1999) model, raising public funds is costless. Consequently, asymmetry of information between the government and public enforcers is not an interesting issue. It does not affect the optimal policy; it only has a distribution role by increasing the share of enforcers at the expense of the government's share of criminal surplus. For a utilitarian government the optimal policy is neutral to such redistribution.

Define $\hat{x}$ as the maximal cost parameter acceptable for the government to hire an agency of type $x$ as an enforcer (that is, $\tilde{p}(\hat{x}) S=0$ ):

$$
\hat{x}=[h S-\lambda G(x) / g(x)] /[1+\lambda]
$$


Corollary 3 The critical level $\hat{x}$ is higher in the context of symmetric information than in the context of imperfect information.

\section{Proof}

For $\lambda=0$ (raising public funds is costless), we have that $\hat{x}=h S$ whereas for $\lambda>0$ we have $\hat{x}<h S$ from (5).

Enforcers of type $\hat{x}<x \leq h S$ are hired within a symmetric information story but not in a context of asymmetric information. The motivation is that enforcers have to be deterred from imitating less cost effective agencies by paying an information rent. By reducing the upper bound on acceptable enforcement costs, the government reduces the cost of an information rent. The consequence is that the least cost effective agency in a context of asymmetric information is more effective than the least cost effective agency in a context of symmetric information. On average, the agencies are more cost effective in a context of asymmetry rather than symmetry of information.

\section{Conclusion}

This paper has extended the theory of optimal law enforcement to the case of asymmetry of information between the government and the public enforcement agency. We have shown that such asymmetry of information affects negatively the probability of apprehension and punishment (and hence positively the proportion of offenses committed) as long as raising public funds is costly.

This paper is directly related to the literature that discusses the advantages of using private enforcement, in particular Polinsky (1980) and Shavell (1993). A private enforcement agency chooses the probability of apprehension and punishment whereas a public enforcement agency simply complies with the probability set by the government. A private enforcer manipulates apprehension and detection to increase profits (naturally does not seek to deter offenses completely). A public enforcer manipulates the cost of complying 
with the probability set by the government to increase the information rent.

In a world where raising public funds is costless, we have shown that asymmetry of information between the government and enforcers does not affect the optimal policy. Consequently, we point out that public enforcement is preferred to private enforcement since, as Polinsky (1980) has shown, the private enforcer might choose a lower than optimal probability even when the government offers a large reward.

When raising public funds is costly, both private and public enforcement lead to a probability of apprehension and punishment different from the optimal one. Depending on the information rent, on one hand, and the private reward and market structure ${ }^{5}$, on the other hand, we can find that private enforcement could be superior to public enforcement.

\section{References}

1. G. S. Becker, 1968, Crime and Punishment: An Economic Approach, Journal of Political Economy, Vol. 76. Pages 169-217.

2. G. S. Becker and G. J. Stigler, 1974, Law Enforcement, Malfeasance and Compensation of Enforcers, Journal of Legal Studies, Vol. 3. Pages $1-18$.

3. D. D. Friedman, 1984, Efficient Institutions for the Private Enforcement of Law, Journal of Legal Studies, Vol. 13. Pages 379-397.

4. N. Garoupa, 1997a, The Theory of Optimal Law Enforcement, Journal of Economic Surveys, Vol. 11. Pages 267-295.

5. N. Garoupa, 1997b, A Note on Private Enforcement and Type I Error, International Review of Law and Economics, Vol. 17. Pages 423-429.

6. N. Garoupa and D. Klerman, 1999, Corruption and Private Law Enforcement with Illustrations from English History, mimeo.

\footnotetext{
${ }^{5}$ Polinsky (1980) shows that enforcement in a monopolistic market is more problematic than in a competitive market.
} 
7. J.-J. Laffont and J. Tirole, 1993, A Theory of Incentives in Procurement and Regulation, MIT Press: Cambridge, Massachusetts.

8. W. M. Landes and R. A. Posner, 1975, The Private Enforcement of Law, Journal of Legal Studies, Vol. 4. Pages 1-46.

9. W. A. Niskanen, 1994, Bureaucracy and Public Economics, The Locke Institute, Edwrad Elgar : Cheltenham, England.

10. A. M. Polinsky, 1980, Private versus Public Enforcement of Fines, Journal of Legal Studies, Vol. 9. Pages 105-127.

11. A. M. Polinsky and S. Shavell, 1999, The Economic Theory of Public Enforcement of Law, Journal of Economic Literature, forthcoming.

12. S. Shavell, 1993, The Optimal Structure of Law Enforcement, Journal of Law and Economics, Vol. 36. Pages 255-287. 